\title{
THE EFFECT OF PARASITISM ON CLOVER ROOT WEEVIL FLIGHT CAPABILITY
}

\author{
T.M. EDEN, M. DONALD and P.J. GERARD \\ AgResearch, Ruakura Research Centre, Private Bag 3123, \\ Hamilton, New Zealand \\ Corresponding author: tina.eden@agresearch.co.nz
}

\begin{abstract}
The Irish strain of Microctonus aethiopoides was released in New Zealand in 2006 to help suppress populations of the clover pest, clover root weevil (Sitona lepidus). A study was undertaken to determine if this parasitoid will be passively dispersed through flight activity by parasitized hosts. In the laboratory, Irish M. aethiopoides parasitized equally hosts with or without flight muscles and subsequent presence of parasitoid eggs or first instar larvae had no effect on the propensity for S. lepidus to prepare to take flight during laboratory observations. In the field, significantly fewer clover root weevil with flight muscles were found to be parasitized compared to those without flight muscles, and those that were parasitized contained predominantly eggs and first instar larvae. The results were compared with other Microctonus biocontrol agents released in New Zealand and it was concluded that passive dispersal should play a major role in dispersing Irish $M$. aethiopoides in New Zealand, especially in warm, dry summers.
\end{abstract}

Keywords: Microctonus aethiopoides, Sitona lepidus, parasitism, flight.

\section{INTRODUCTION}

Experimental releases of the Irish strain of Microctonus aethiopoides Loan (Hymenoptera: Braconidae), a biocontrol agent introduced to control the clover root weevil (Sitona lepidus), commenced in New Zealand in late summer 2006 (Gerard et al. 2007). This parasitoid attacks adult weevils, rendering females sterile upon parasitism, and killing the weevil upon emergence of the parasitoid larva (Gerard et al.2007). Results during the first year following release showed that Irish M. aethiopoides had the ability to establish and multiply rapidly, and that it could persist under adverse conditions (Gerard et al. 2007). Therefore work commenced on a nationwide dispersal strategy.

One factor essential to planning a dispersal strategy is knowledge of whether Irish $M$. aethiopoides will be passively carried to distant sites through flight activity by parasitized S.lepidus. When the Moroccan biotype of M.aethiopoides was introduced to control Sitona discoideus Gyllenhall in Australia and New Zealand, dispersal from release sites was rapid through the passive dispersal of larvae inside adult hosts on obligatory flights to and from aestivation sites (Aeschlimann 1983). However, S. lepidus does not aestivate and flight capability is facultative, with flight muscle development predominantly associated with warm, dry summer conditions and limited clover (Gerard \& Arnold 2002). Therefore it was of concern that in the second winter following release, Irish $M$. aethiopoides had been detected only $2 \mathrm{~km}$ at most from any of the release sites. Similar slow dispersal was observed with Microctonus hyperodae Loan, which following release in Canterbury in 1991 to control Listronotus bonariensis (Kuschel), dispersed on average under $2 \mathrm{~km} / \mathrm{year}$ (Goldson et al. 1999a) and still had limited South Island coverage in 2002 (McNeill et al. 2002).

As a slow dispersal rate would increase markedly the effort required to establish the biocontrol agent in all S. lepidus affected areas, further investigations on flight capability of parasitized S. lepidus were undertaken in 2008. This paper reports on a laboratory experiment designed to determine if S. lepidus are able to fly when parasitized by Irish M. aethiopoides, and compares results with field observations. 


\section{Laboratory experiment}

\section{METHODS}

Sitona lepidus adults were collected from the field in January and February 2008 and randomly sorted into batches of 100 . Each batch was caged with two M. aethiopoides adults and held for $7-18$ days at $20^{\circ} \mathrm{C}$ in $16: 8 \mathrm{~h}$ light:dark. Fresh clover, water and $20 \%$ sugar solution was provided in the cage at all times. This was replicated seven times.

After 7-18 days exposure, individual cages were placed on the lab bench in bright sunlight with their lids removed. Temperatures were generally above $25^{\circ} \mathrm{C}$. All weevils that responded to the sunlight by fanning their elytra during a $30 \mathrm{~min}$ observation period were collected, labelled and frozen at $-20^{\circ} \mathrm{C}$ for later dissection. A sample of the same number of weevils from the same cages comprising those that did not fan their elytra was also collected and frozen.

To confirm that fanning of elytra was a behaviour that strongly correlated to the ability of S. lepidus to fly, 50 field-collected S. lepidus were placed in a 10 litre container on the same laboratory bench in full sun with the lid removed. Ten weevils fanning their elytra were collected, then individually observed under the same conditions but for a longer period to see whether they achieved lift-off. A cut-off time of $1 \mathrm{~h}$ was arbitrarily imposed. All weevils were recovered and frozen for later dissection.

Each weevil was dissected under a binocular microscope at $20 \mathrm{x}$ magnification and presence, number and developmental stage of any endo-parasitoids present was recorded. The degree of flight muscle development was assigned a score from $0=$ no flight muscles present through to 3 = flight muscles fully developed.

\section{Field data}

As part of the S. lepidus biocontrol programme, S. lepidus adult populations from experimental release sites in Waikato, Hawke's Bay and Manawatu are sampled at monthly intervals and dissected as above (Gerard et al. 2007). To ascertain if there was a difference in the field in parasitism levels between adult weevils with or without flight capability, data from all samples containing both parasitized weevils and adults with fully developed flight muscles (score of 3) were collated and analysed. Weevils with partially developed flight muscles were excluded from the analyses.

\section{Statistical analyses}

Experimental data were analysed using binomial regression analysis to allow for the varying parasitoid exposure periods. Field data were analysed using binomial regression to take into account site $\times$ replicate $\times$ date interactions.

\section{Laboratory experiment}

\section{RESULTS}

Of the 10 individual weevils observed for flight activity, seven achieved lift-off during the 1 hour observation period. Dissection revealed that all 10 weevils had fully developed wing muscles, thus providing evidence that fanning of elytra is a behaviour that strongly correlates to flight capability.

In total 102 weevils were dissected from the seven exposure cages, including 51 that exhibited fanning of their elytra and an equivalent 51 that did not. All weevils that were observed to fan their elytra had the maximum flight muscle score of 3 . Although equal numbers of fanning and non-fanning weevils were collected, dissection revealed that $17 \%$ of the non-fanning weevils had a maximum flight muscle score of 3 , and should therefore have been physically capable of flight. These nine weevils were transferred to the "fully-developed flight muscles" data set for analysis of parasitism. As only one weevil had a flight muscle score between 0 and 3 , it was excluded from analyses. The results of the dissection of weevils exposed to parasitoids in the laboratory are presented in Figure 1. There was no significant difference $(\mathrm{P}=0.52)$ in parasitism levels in weevils with fully developed flight muscles $(38 \pm 8 \%)$ and those without flight muscles $(30 \pm$ $9 \%$ ). Although most weevils had been exposed to M. aethiopoides for up to 18 days at time of dissection, only two parasitoids had reached the second instar (both in adults capable of flight). 


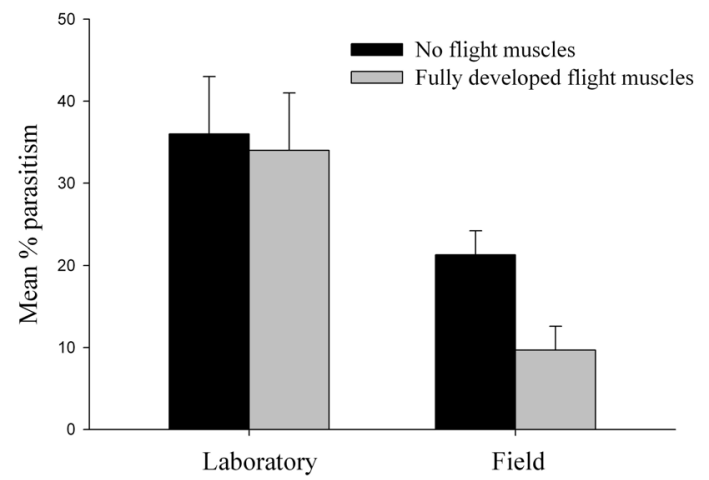

\section{FIGURE 1: Parasitism by Irish $M$. aethiopoides (\%) of $S$. lepidus adults with none or fully developed muscles in laboratory experiments and field collections.}

\section{Field observations}

A total of 25 samples from all four experimental release sites were taken from December to February, averaging 17 S. lepidus adults/sample. Overall, $28 \%$ of weevils in these samples had flight capability. A significantly higher percentage $(\mathrm{P}=0.011)$ of weevils with no flight muscles were parasitized $(21.3 \pm 0.3 \%)$ compared to those with fully developed muscles $(9.7 \pm 0.3 \%)$. While a range of larval instars was present in weevils with no flight muscles, only one second instar parasitoid larva was found in weevils with fully-developed flight muscles, the rest being first instars or eggs.

\section{DISCUSSION}

The laboratory experiment showed that Irish M.aethiopoides females parasitised hosts both with and without fully-developed flight muscles and that the subsequent presence of parasitoid eggs or first instar larvae had no apparent effect on these muscles during the period observed. However, in the field where all larval instars were present, parasitism was lowest in S.lepidus with flight muscles, and when parasitized, the weevils with flight muscles almost all contained either eggs or first instars. No weevils containing $3^{\text {rd }}$ or later instar parasitoid larvae had wing muscles. The most likely explanation is that as the larva matures and draws on more resources from the host, the weevil absorbs its flight muscles. Flight capability in S. lepidus is facultative and stress-induced changes in adult physiology have been reported previously (Gerard \& Arnold 2002).

These results are similar to published observations on the other two Microctonus weevil biocontrol agents previously released in New Zealand. In the case of the Moroccan M. aethiopoides and S. discoideus, Goldson et al. (1990) found parasitized adults trapped in flight going to aestivation sites all contained first instar larvae in sympathetic diapause, but $10.7 \%$ of those trapped on return flights contained larvae with development beyond first instar. Barratt \& Johnstone (2001) carried out a laboratory experiment showing that when a full range of parasitoid developmental stages were present, there were significantly fewer parasitized than unparasitized S. discoideus with flight muscles. They suggested that flight muscles of $S$. discoideus are absorbed as the parasitoid develops so as to maximise resources available to the developing parasitoid.

The field observations reported match those of Goldson et al. (1999b) who showed that L. bonariensis adults trapped in flight appeared to have much lower levels of parasitism by $M$. hyperodae than ground populations during the same period and that only eggs and first instar were observed in trapped adults. Therefore, as with S. lepidus, one can infer L. bonariensis adults containing later instars do not fly. Goldson et al. (1999b) concluded that the low levels of parasitism in flying adults may have contributed to the slow dispersal rate of $M$. hyperodae following release. 
Laboratory studies have shown S. lepidus physiology changes in response to environmental conditions with few adults having flight muscles in cool moist conditions and a high proportion of the population having flight muscles in hot, drought conditions (Gerard \& Arnold 2002). Therefore passive parasitoid dispersal by host flight is more likely during warm, dry summers, such as was experienced in 2007/08. This has been demonstrated in the field by the collection of parasitized S. lepidus adults this autumn at a site at Rissington, $12 \mathrm{~km}$ from the Hawke's Bay release site that has been monitored regularly in anticipation of parasitoid arrival. Conversely, cool, moist conditions in December and early January, such as in summer 2006/07, would hamper passive dispersal by not only reducing the proportion of weevils with flight capability, but also restricting the number of warm sunny days when flight occurs. This would be compounded if poor weather occurred during the window of opportunity when the mid-summer Irish $M$. aethiopoides generation are predominantly eggs and first instars.

In conclusion, Irish $M$. aethiopoides does parasitize $S$. lepidus adults with flight capability and it is predicted that these weevils will retain flight capability while the parasitoids are eggs or first instars. Therefore, passive dispersal from release sites inside host weevils should play a role in dispersing Irish $M$. aethiopoides in New Zealand, especially in warm, dry summers.

\section{ACKNOWLEDGEMENTS}

The authors sincerely thank Catherine Cameron for data analysis, and the rest of our clover root weevil biocontrol team, in particular Derrick Wilson, Mike Slay, Chris Mercer and Kieran Miller, who undertook the weevil sampling and collections. The clover root weevil biocontrol programme is funded by New Zealand Foundation for Research, Science and Technology (Contract number LINX0304), DairyNZ and Meat \& Wool New Zealand.

\section{REFERENCES}

Aeschlimann J-P 1983. Sources of importation, establishment and spread in Australia, of Microctonus aethiopoides Loan (Hymenoptera: Braconidae), a parasitoid of Sitona discoideus Gyllenhal (Coleoptera: Curculionidae). Australian Journal of Entomology 22: 325-331.

Barratt BIP, Johnstone PD 2001. Factors affecting parasitism by Microctonus aethiopoides (Hymenoptera: Braconidae) and parasitoid development in natural and novel host species. Bulletin of Entomological Research 91: 245-253.

Gerard PJ, Eden TE, Hardwick S, Mercer CF, Slay MWA, Wilson DJ 2007. Initial establishment of the Irish strain of Microctonus aethiopoides in New Zealand. New Zealand Plant Protection 60: 203-208.

Gerard PJ, Arnold ED 2002. Influence of climate regime on clover root weevil adult survival and physiology. New Zealand Plant Protection 55: 241-245.

Goldson SL, Proffitt JR, McNeill MR 1990. Seasonal biology and ecology in New Zealand of Microctonus aethiopoides (Hymenopters: Braconidae), a parasitoid of Sitona SPP. (Coleoptera: Curculionidae), with special emphasis on atypical behaviour. Journal of Applied Ecology 27: 703-722.

Goldson SL, Proffitt JR, McNeill MR, Baird DB 1999a. Linear patterns and build up of the introduced parasitoid Microctonus hyperodae (Hymenopters: Braconidae) in Canterbury, New Zealand. Bulletin of Entomological Research 89: 347-353.

Goldson SR, Proffitt JR, Baird DB 1999b. Listronotus bonariensis (Coleoptera: Curculionidae) flight in Canterbury. New Zealand. Bulletin of Entomological Research 89: 423-431.

McNeill MR, Kean JM, Goldson SL. 2002. Parasitism by Microctonus aethiopoides on a novel host, Listronotus bonariensis, in Canterbury pastures. New Zealand Plant Protection 55: 280-286. 